\title{
ANALYSIS AND EVALUATION OF TRAPEZOIDAL SPEED HUMPS AND THEIR IMPACT ON THE DRIVER
}

\author{
Vilma JASIŪNIENE ${ }^{1 *}$, Gintarè POCIŪTE் ${ }^{2}$, Audrius VAITKUS ${ }^{3}$, Kornelija RATKEVIČIŪTĖ ${ }^{4}$, \\ Algis PAKALNIS ${ }^{5}$ \\ $1,2,3,{ }^{4}$ Road Research Institute, Vilnius Gediminas Technical University, Vilnius, Lithuania \\ ${ }^{5}$ Dept of Transport Engineering, Kaunas University of Technology, Kaunas, Lithuania
}

Received 09 June 2017; accepted 21 September 2017

\begin{abstract}
Operating speed is one of the leading safety risk factors, which increases accident risk and influences accident severity. Speeding is the leading cause of accidents and the most common road traffic offense. The key measures of speed control are educational activities and engineering traffic calming measures. This paper presents an investigation of trapezoidal speed humps - one of the traffic calming measures - and their impact on the driver and the occupants of the vehicle. The level of discomfort to the driver and the occupants, caused by vibrations when the vehicle passes the speed hump, was determined during experimental research. The discomfort level, calculated by three methods, indicated the leading cause of discomfort generated by the analysed trapezoidal speed humps.
\end{abstract}

Keywords: discomfort in the vehicle, speed, traffic calming measures, trapezoidal speed hump, whole-body vibration.

\section{Introduction and literature review}

One of the most significant problems on roads and streets is road safety. Various international organizations, countries together and individually indicate targets to decrease accidents and fatalities on roads. In 2015, the World Health Organization set a national safety target for reaching the sustainable development goals - by 2020 , to halve the number of global deaths and injuries from accidents. According to the Towards a European Road Safety Area: Policy Orientations on Road Safety 2011-2020, road safety aims to reduce the number of fatalities in Europe by half by 2020. In Lithuania, the National Road Safety Development Programme for 2011-2017 was carried out with the strategic goal - become one of the ten best European Union countries according to the deaths of road users per 1 million inhabitants.

Figure 1 shows the change in road accidents and the number of people killed or injured on Lithuanian roads in 2000-2016. Since 2015, a significant decrease in fatal and injury accidents has been observed: the number of injuries has decreased twice, the number of fatal accidents - by three times. This change was achieved by implementing combined engineering and educational measures, also by increasing legal responsibility for road traffic offences.

One of the leading causes of accidents and one of the most common road traffic offences is speeding. Regardless a higher speed limit on the roads of a particular category, $40-50 \%$ of drivers still exceed the speed limit. According to the Global Status Report on Road Safety 2015, issued by the World Health Organization, the risk of death in a road accident for a pedestrian and cyclist depends directly on the operating speed, with the increasing operating speed, the risk of the accident also increases. Results from investigations of collisions involving pedestrians and vehicles shows that $90 \%$ of pedestrians survive being hit by a vehicle at operating speed of $30 \mathrm{~km} / \mathrm{h}$, whereas only $20 \%$ survive at operating speed of $50 \mathrm{~km} / \mathrm{h}$, the chance to survive for a pedestrian or cyclist is nearly zero if hit by a vehicle at a speed of $80 \mathrm{~km} / \mathrm{h}$ (OECD, ECMT, 2006).

The relationship between the mean operating speed and accident rate, also the dependence between the risk of accident and operating speed is shown in Figure 2.

Operating speed is usually controlled by educational activities (road safety campaigns, road safety projects with communities, students, clergy) and engineering traffic calming measures, which physically prevent road users from breaking traffic rules and in case of an accident minimizes accident severity.

This paper analyses vertical traffic calming measures trapezoidal speed humps and their impact on road users. According to Highway Safety Manual 2010, issued by Ameri-

${ }^{*}$ Corresponding author. E-mail: vilma.jasiuniene@vgtu.lt 


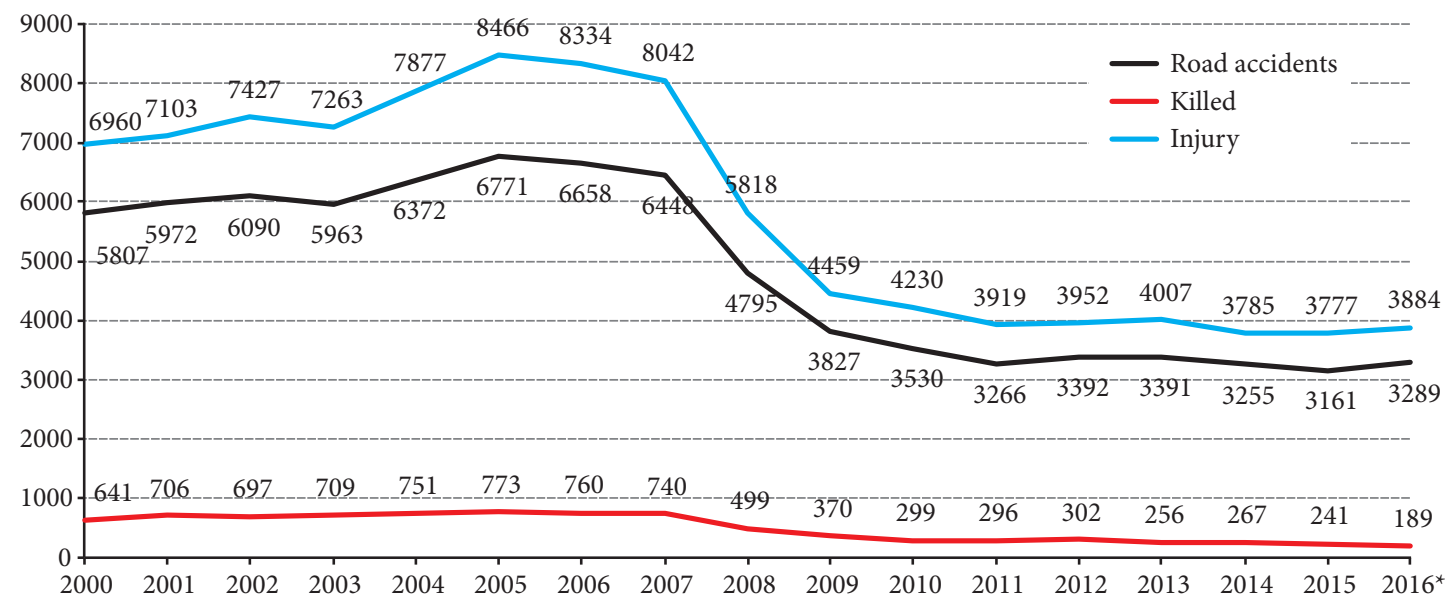

Figure 1. Change in the number of accidents on Lithuanian roads in 2000-2016 (data provided by the Lithuanian Road Administration under the Ministry of Transport and Communications)

can Association of State Highway and Transportation Officials, implementation of engineering traffic calming measures reduces accidents on roads by $30 \%$.

In Lithuania, R ISEP 10 Recommendations for the Design and Application of Engineering Traffic Safety Measures, approved by the Lithuanian Road Administration under the Ministry of Transport and Communications, regulate the installation of trapezoidal speed humps. Geometrical parameters of trapezoidal speed humps, i.e., height, length, and slope, depending on the speed (Table 1).

Implementation of traffic calming measures in Lithuania has been increasing. Most literature sources analyse the impact of speed humps on the operating speed, though it is essential to figure out the impact of speed humps on the environment and on the road users, i.e., vehicle drivers and occupants.

The research aim is to introduce shocks and vibration levels when a car passes a speed hump at speed higher than the speed limit. The geometry of a hump is a significant factor in altering the level of these shocks and specifying the speed limit (Khorshid, Alkalby, \& Kamal, 2007). Watts (1973) stated that the ideal speed hump should be crossed without damage to vehicle or load, without loss of control or driver comfort.

The occupants are exposed to whole-body mechanical vibration during their daily trip. The whole-body vibrations originate from two different type of forces the random and the sudden forces designated as a shock (Granlund, Ahlin, \& Lundström, 2000). When the tires hit a hump or sink into a pothole, a shock occurs. If this shock is strong enough, it causes severe spinal injury (Bowrey, Thomas, Evans, \& Richmond, 1996; Dupuis \&

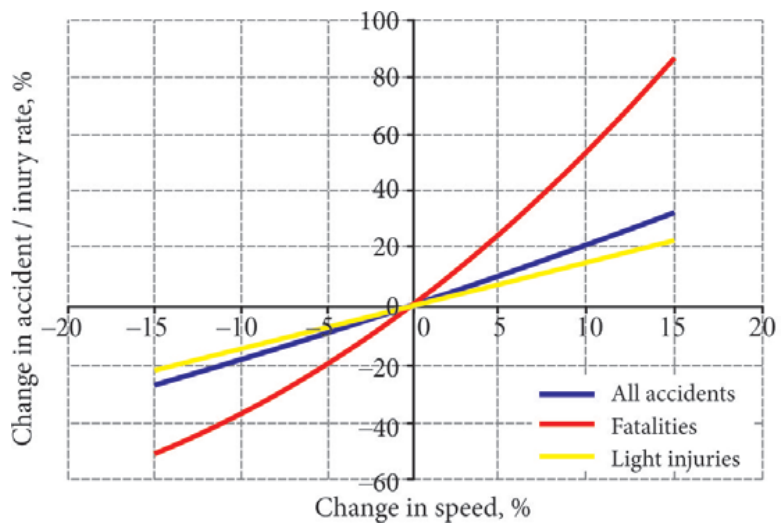

Figure 2. The relationship between the change in the mean operating speed and accident rates (Elvik, 2009)

Zerlett, 1986) and other harm (Ji, Eger, \& Dickey, 2017; Patel \& Vasudevan, 2016). Also among many categories involved, professional drivers are one of the most exposed groups, as exposure time may last for the working period.

The reported research by Rosegger (1960) claimed that shaking and jolting may lead to macrotrauma and microtrauma to the vertebrae. The work by Troup (1988) argued that transmitted road-shock is a source of back problems. Johanning, Fischer, Christ, Gores, \& Landsbergis (2002), Sandover (1998), Paddan \& Griffin (2002), Lings \& Leboeuf-Yde (2000), and Teschke, Nicol, Davies, and Ju (1999) concluded that the drivers of certain vehicles are at risk for lower back problems. The study on the effect of long-term exposure to whole-body vibration by Wikström, Kjellberg, and Landström (1994) concluded that

Table 1. Dimensions of trapezoidal speed humps depending on the speed according to the R ISEP 10

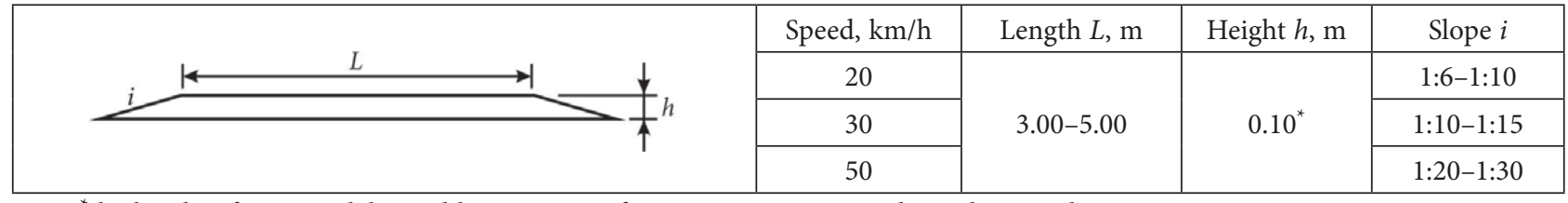

Note: ${ }^{*}$ the height of trapezoidal speed hump ranges from $0.08 \mathrm{~m}$ to $0.12 \mathrm{~m}$ depending on the situation 
many repeated shocks with a sufficient level and duration might lead to back problems. The experimental work by Granlund, Lindstroms, and Vägen (2003) demonstrated a high level of shocks introduced to the occupants while crossing speed humps. There are several reported Scandinavian injury cases when passing the traffic calming speed humps by bus (Khorshid, Alkalby, \& Kamal, 2007).

The impact on road safety - the level of discomfort to drivers and occupants, as well as evaluation of the possible loss of vehicle control, caused by the vibration when passing trapezoidal speed humps (Table 1) were determined during experimental research. Jaganmohan, Sivapirakasham, Balasubramanian, and Sreenath (2014) conducted similar research aimed at measuring the whole-body vibration transmitted to the driver as well as other passengers during the trip by bus and to compare the results obtained with the comfort chart and health guidance criteria set in ISO 2631-1:1997.

\section{Experimental methods}

\subsection{Research object}

This research aimed to analyse the impact of trapezoidal speed humps on the driver and the occupants of the vehicle. Trapezoidal speed humps were investigated on the national and regional roads of Vilnius region in cooperation with the State Enterprise "Vilniaus regiono keliai".

The essential data about trapezoidal speed humps in Vilnius region were obtained. By the year 2016, 224 trapezoidal speed humps were installed on the roads of national significance in Vilnius region. Fifty-eight trapezoidal speed humps were randomly selected for the experiment, all of them made of asphalt. The service period of the investigated trapezoidal speed humps varied from 1 to 9 years.

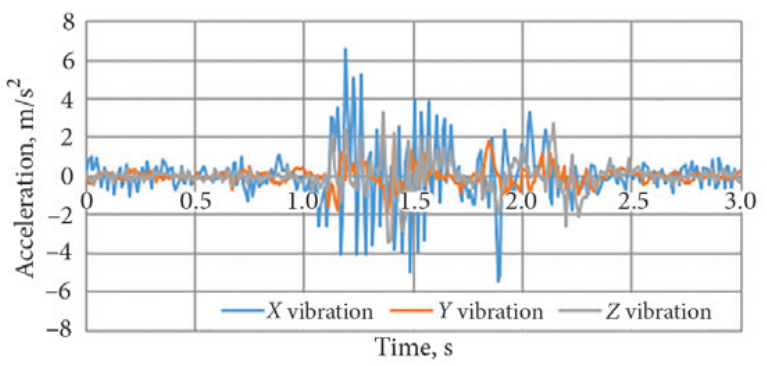

Figure 3. Acceleration over time

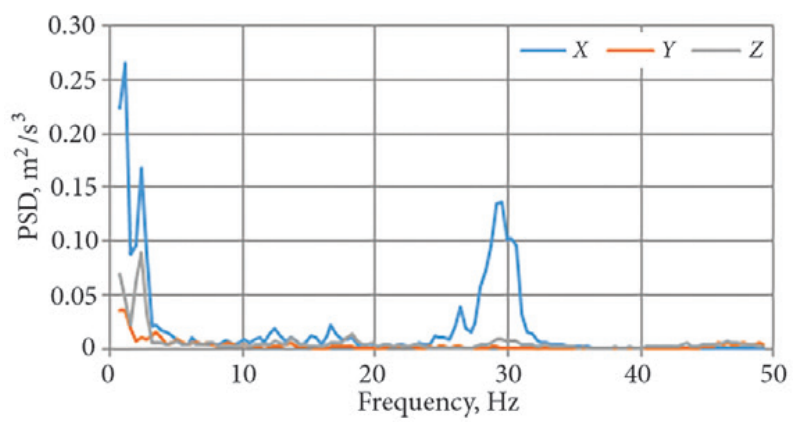

Figure 4. Power Spectral Density

\subsection{Experiment methodology}

The amount of shock, which might harm the health of occupants, depends on the operating speed, speed hump geometry, vehicle type, the position of occupants, and evaluation method (Khorshid, Alkalby, \& Kamal, 2007). To figure out the impact of a trapezoidal speed hump on the driver and the occupant vibrations were analysed depending on the slope of a trapezoidal speed hump.

The experiment was carried out by a mobile phone. A car phone holder was attached to the windscreen. The driver was the only person in the car during the experiment. The experiment procedure was as follows:

1. Data on the vibrations and the frequencies inside the vehicle were determined using the vibration meter VibSensor in a mobile phone when a car was passing through the speed hump at a permissible speed. Vibrations were divided into three orthogonal axes depending on the direction in which it affects the human body:

- vertical vibrations - from feet towards the head (in this case $X$ vibration (axis));

- horizontal vibrations - from right to left (in this case $Y$ vibration (axis));

- horizontal vibrations - from the chest to the back (in this case $Z$ vibration (axis)).

Two charts were obtained showing:

- acceleration over time (Figure 3);

- Power Spectral Density (PSD) (Figure 4).

2. Using a Digital Spirit Level the approach slope of the speed hump was measured (a Digital Spirit Level measures angles and inclinations).

Figure 3 shows vibration changes with the change in acceleration (in $\mathrm{m} / \mathrm{s}^{2}$ ) over time in $X, Y$, and $Z$-axes. The chart shows time when the vehicle reaches the hump after the first second. At mentioned time vibration shocks increase up to seven times. The chart (Figure 3) indicates much higher vibrations, produced by the vehicle passing the speed hump, than those passing a flat surface.

Figure 4 shows the Power Spectral Density (PSD) (in $\mathrm{m}^{2} / \mathrm{s}^{3}$ ) indicating acceleration energy distribution in a specific frequency range. The frequency resonances are $1.16 \mathrm{~Hz}, 2.3 \mathrm{~Hz}$, and $29 \mathrm{~Hz}$.

\section{Results}

Vibration tests were carried out when driving at a permissible speed of $30 \mathrm{~km} / \mathrm{h}$ or $50 \mathrm{~km} / \mathrm{h}$. Maximum vibration values were produced on the vertical axis, i.e., vibrations from the feet towards the head. The maximum vertical vibration shocks range from $2.25 \mathrm{~m} / \mathrm{s}^{2}$ to $20.76 \mathrm{~m} / \mathrm{s}^{2}$. The most common frequency resonances are $1.6 \mathrm{~Hz}$ and $30 \mathrm{~Hz}$.

The results of the experiment according to the slopes of trapezoidal speed hump and vibrations showed no linear dependence on vertical vibrations inside the vehicle and the approach slope of a trapezoidal speed hump. It is complicated to accurately determine the slope of a hump because of deterioration, corrugation and other damages, so the results could be influenced according to this fact. 
Based on the vibration data, it was decided to analyse the impact of the discomfort of the driver and the occupants. The effect of trapezoidal speed humps on the driver and the occupants was evaluated by:

1. Vertical acceleration values (Piersol \& Paez, 2009);

2. The standard LST ISO 2631-1:2004 Mechanical Vibration and Shock - Evaluation of Human Exposure to Whole-Body Vibration. Part 1: General Requirements; 3. Vibration Dose Value (VDV).

\subsection{Vertical acceleration values}

Piersol and Paez in 2009 stated about values of vibration unit shocks in the vertical direction. However, these values are about, because adverse vibration effects are influenced by age, physical condition, clothing, weight, and many other factors. If the permissible values are exceeded, fractures of the lumbar and thoracic vertebrae occur first. While in and of itself, this injury may not be classified as severe, small changes in orientation may be enough to involve the spinal cord, an injury being extraordinary severe and life-threatening. Neck injuries from vertical accelerations seem to occur at considerably higher levels (Piersol \& Paez, 2009).

The research results, processed according to Piersol and Paez (2009), are shown in Figure 5. The majority of vertical unit vibrations, caused by trapezoidal speed humps, were found to hurt the driver and the occupant. Only about 5\% of trapezoidal speed humps caused no discomfort, and 35\% were above the comfort limit. Even 60\% of trapezoidal speed humps exceeded the limit of very undesirable discomfort.

\subsection{The standard LST ISO 2631-1:2004}

The obtained research data was evaluated based on the Lithuanian standard LST ISO 2631-1:2004. The standard imposes no strict requirements for the valid vibration limit. It provides reference values for generally weighted accelerations, affecting passengers and causing comfort or discomfort during the trip, $\mathrm{m} / \mathrm{s}^{2}$ :

- less than 0.315 - no discomfort;

- 0.315-0.63 - a bit uncomfortable;

- 0.5-1.0 - quite uncomfortable;

- 0.8-1.6 - uncomfortable;

- 1.25-2.5 - very uncomfortable;

- more than 2 - especially uncomfortable.

According to the LST ISO 2631-1:2004 all the analysed trapezoidal speed humps were determined as causing discomfort (Figure 6). $88 \%$ of humps caused the feeling from quite uncomfortable to very uncomfortable, and $12 \%$ of humps represented the upper values - they were mainly uncomfortable.

The results could be more accurate according to the LST ISO 2631-1:2004 when evaluating comfort, if calculations were done by using the weighted root-mean-square acceleration to determine the effect of the whole-body vibrations on the driver and the occupants.

\subsection{The Vibration Dose Value}

Based on the Regulations for the Exposure of Workers to the Risks of Vibration, for the whole-body vibration:

- the daily exposure limit value, calculated for eighthour working time, shall be less than $1.15 \mathrm{~m} / \mathrm{s}^{2}$ or a VDV shall be less than $21 \mathrm{~m} / \mathrm{s}^{1.75}$;

- the daily exposure action value, calculated for eighthour working time, shall be less than $0.5 \mathrm{~m} / \mathrm{s}^{2}$ or a Vibration Dose Value (VDV) shall be less than $9.1 \mathrm{~m} / \mathrm{s}^{1.75}$.

The Vibration Dose Value was calculated according to the Regulations for the Exposure of Workers to the Risks of Vibration in Lithuania and Practical Recommendations for Applying Regulations for the Exposure of Workers to the Risks of Vibration in Lithuania.

Based on the LST ISO 2631-1:2004 the vibration assessment method according to the VDV was determined as proper. The peak factor was used to figure out if the evaluation method is suitable to describe vibration intensity by the impact on human. The core of vibration evaluation method is usually sufficient (LST ISO 2631-1:2004), when the peak factor is less or equal to 9 . The peak factors, obtained in this research, are less than 9. In the main assessment method, the weighted root-mean-square acceleration was used.

The Vibration Dose Value was calculated by specifying that during 8 hours of the working time the calculated effect of acceleration over humps lasts 96 seconds. The root-mean-square acceleration value was calculated for 3

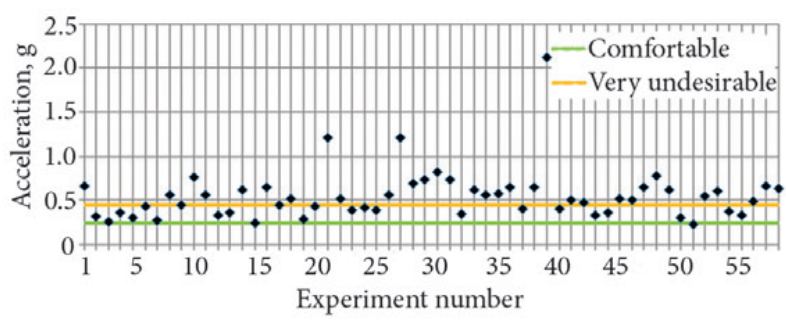

Figure 5. Effect of the analysed trapezoidal speed humps according to the vertical acceleration values by Piersol and Paez (2009)

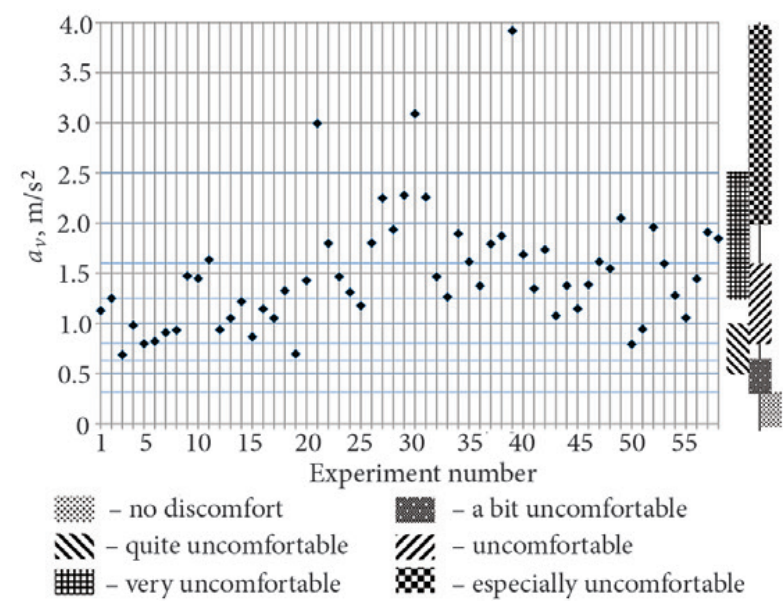

Figure 6. Effect of the analysed trapezoidal speed humps on driving comfort according to the LST ISO 2631-1:2004 


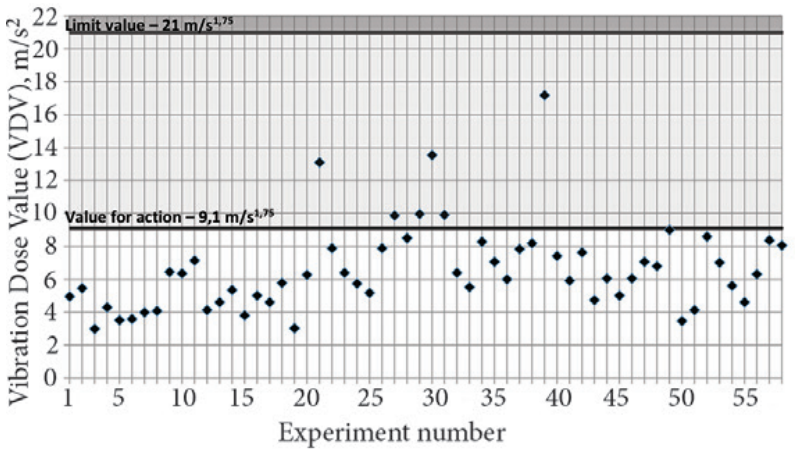

Figure 7. Distribution of the analysed trapezoidal speed humps according to the Vibration Dose Value

seconds time interval and 32 periods since it is the average number of speed humps passed daily in normal conditions by professional drivers (Khorshid, Alkalby, \& Kamal, 2007). However, the number of passed daily speed humps may be higher, as in Teschke, Nicol, Davies, and Ju (1999) study where this number was 264 . It was assumed that the same speed hump was passed daily 32 times.

The distribution of VDV of the analysed trapezoidal speed humps is shown in Figure 7.

Calculations of the VDV showed that $10 \%$ of trapezoidal speed humps exceeded the daily exposure value.

\section{Conclusions}

1. Speeding is one of the most common causes of accidents, which affects the risk of the accident and also affects the accident severity. Currently, 40-50\% of drivers in the European Union exceed the speed limit.

2. Speed humps are a very effective traffic calming (speed control) measure, relatively easy to install. However, speed humps have also disadvantages related to increased noise and pollution caused by decelerating and accelerating vehicles. Speed humps create potential negative vibrations inside the vehicle, and for the neighbouring buildings, they slow down emergency vehicles.

3. The maximum vertical vibration shocks, when the vehicle passes the analysed humps at a permissible speed, range from $2.25 \mathrm{~m} / \mathrm{s}^{2}$ to $20.76 \mathrm{~m} / \mathrm{s}^{2}$. Three methods were used to evaluate the effect of trapezoidal speed humps on the driver and the occupants:

- vertical acceleration values showed that $60 \%$ of humps exceeded the limit of very undesirable discomfort;

- investigation according to the LST ISO 2631-1:2004 Mechanical Vibration and Shock - Evaluation of Human Exposure to Whole-body Vibration. Part 1: General Requirements has determined that all the analysed trapezoidal speed humps cause discomfort, $12 \%$ - were particularly uncomfortable;

- the vicbration dose value, calculated according to the Regulations for the Exposure of Workers to the Risks of Vibration in Lithuania, showed that $10 \%$ of trapezoidal speed humps exceeded the daily exposure value.
4. The results of the research of slopes of speed humps and vibrations indicated that there is no linear dependence between vertical vibrations inside the vehicle and the approach slope. The complicated measuring process of approach slopes may have influenced the above result. It would be appropriate to repeat the test using more precision test devices to assess the impact on the discomfort of the driver and the occupants based on the slope of a trapezoidal speed hump.

\section{Acknowledgment}

The authors would like to thank the State Enterprise "Vilniaus regiono keliai" for the data of speed humps in Vilnius region.

\section{References}

AASHTO (American Association of State Highway and Transportation Officials). (2010) Highway safety manual 2010 (1st ed.). AASHTO.

Bowrey, D., Thomas, R., Evans, R., \& Richmond, P. (1996). Road humps: accident prevention or hazard? Emergency Medicine Journal, 13(4), 288-289. https://doi.org/10.1136/emj.13.4.288

Dupuis, H., \& Zerlett, G. (1986). The effects of whole-body vibration. Springer Science \& Business Media.

https://doi.org/10.1007/978-3-642-71245-6

Elvik, R. (2009). The Power Model of the relationship between speed and road safety: update and new analyses (No. 1034/2009).

Granlund, J., Ahlin, K., \& Lundström, R. (2000). Whole-body vibration when riding on rough roads. Burlang (Sweden): Swedish National Road Administration.

Granlund, J., Lindström, F., \& Vägen, R. (2003, July). Design of a shock-free speed hump. Proceedings, 10th international congress on sound and vibration. Stockholm, Sweden (Vol. 10).

ISO 2631-1:1997: Mechanical vibration and shock - Evaluation of human exposure to whole-body vibration - Part 1: General requirements.

Jaganmohan, M. R., Sivapirakasham, S. P., Balasubramanian, K. R., \& Sreenath, K. T. (2014). Investigation of whole body vibration on urban midi bus. Applied Mechanics and Materials, 592, 2066-2070. Trans Tech Publications.

https://doi.org/10.4028/www.scientific.net/AMM.592-594.2066

Ji, X., Eger, T. R., \& Dickey, J. P. (2017). Evaluation of the vibration attenuation properties of an air-inflated cushion with two different heavy machinery seats in multi-axis vibration environments including jolts. Applied Ergonomics, 59, 293301. https://doi.org/10.1016/j.apergo.2016.06.011

Johanning, E., Fischer, S., Christ, E., Göres, B., \& Landsbergis, P. (2002). Whole-body vibration exposure study in US railroad locomotives - an ergonomic risk assessment. AIHA Journal, 63(4), 439-446. https://doi.org/10.1080/15428110208984732

OECD (Organisation for Economic Co-operation and Development), ECMT (European Conference of Ministers of Transport). (2006). Speed management. Report, ITRD Number E130442.

Khorshid, E., Alkalby, F., \& Kamal, H. (2007). Measurement of whole-body vibration exposure from speed control humps. Journal of Sound and Vibration, 304(3-5), 640-659. https://doi.org/10.1016/j.jsv.2007.03.013 
Lings, S., \& Leboeuf-Yde, C. (2000). Whole-body vibration and low back pain: a systematic, critical review of the epidemiological literature 1992-1999. International Archives of Occupational and Environmental Health, 73(5), 290-297. https://doi.org/10.1007/s004200000118

Lithuanian Road Administration under the Ministry of Transport and Communications. (2017). Statistics of fatal and injury road accidents in Lithuania. Retrieved from http://lakd. lrv.lt/en/sector-activities/traffic-safety

LST ISO 2631-1:2004: Mechanical Vibration and Shock - Evaluation of Human Exposure to Whole-body Vibration. Part 1: General Requirements.

Paddan, G. S., \& Griffin, M. J. (2002). Effect of seating on exposures to whole-body vibration in vehicles. Journal of Sound and Vibration, 253(1), 215-241. https://doi.org/10.1006/jsvi.2001.4257

Patel, T., \& Vasudevan, V. (2016). Impact of speed humps of bicyclists. Safety Science, 89, 138-146. https://doi.org/10.1016/j.ssci.2016.06.012

Piersol, A. G., \& Paez, T. L. (2009). Harris' shock and vibration handbook. New York: McGraw Hill Professional.

Rosegger, R. (1960). Health effects of tractor driving. Journal of Agricultural Engineering Research, 5, 241-275.
Sandover, J. (1998). High acceleration events: an introduction and review of expert opinion. Journal of Sound and Vibration, 215(4), 927-945. https://doi.org/10.1006/jsvi.1998.1604

Teschke, K., Nicol, A. M., Davies, H., \& Ju, S. (1999). Whole body vibrations and back disorders among motor vehicle drivers and heavy equipment operators: a review of the scientific evidence (35 p.). Vancouver, Canada. https://doi.org/10.14288/1.0048193

Troup, J. D. G. (1988). Clinical effects of shock and vibration on the spine. Clinical Biomechanics, 3(4), 232-235. https://doi.org/10.1016/0268-0033(88)90042-3

Watts, G. R. (1973). Road humps for the control of vehicle speeds. Verkeerstechnick, 24 (NLR59 R \& D Rpt.).

Wikström, B. O., Kjellberg, A., \& Landström, U. (1994). Health effects of long-term occupational exposure to whole-body vibration: a review. International Journal of Industrial Ergonomics, 14(4), 273-292. https://doi.org/10.1016/0169-8141(94)90017-5

World Health Organization. (2016). Global Status Report on Road Safety 2015. Retrieved from http://www.who.int/violence_injury_prevention/road_safety_status/2015/en/ 